\title{
COMPETITIVE ELECTROCHEMICAL IMMUNOSENSOR FOR THE DETECTION OF UNFOLDED p53 PROTEIN IN BLOOD AS BIOMARKER FOR ALZHEIMER'S DISEASE
}

Olaya Amor-Gutiérrez ${ }^{1}$, Estefanía Costa-Rama ${ }^{1,2}$, Noemi Arce-Varas ${ }^{3}$, Carmen MartínezRodríguez ${ }^{4}$, Antonello Novelli, ${ }^{3,6,7}$, María Teresa Fernández-Sánchez ${ }^{5,6}$, Agustín CostaGarcia $^{1 *}$

${ }^{1}$ Nanobioanalysis Group, Department of Physical and Analytical Chemistry, University of Oviedo, Oviedo, Spain;

${ }^{2}$ REQUIMTE/LAQV, Instituto Superior de Engenharia do Porto, Instituto Politécnico do Porto, Porto, Portugal;

${ }^{3}$ Department of Psychology, University of Oviedo, Oviedo, Spain;

${ }^{4}$ University Hospital of Cabueñes, Gijón, Spain;

${ }^{5}$ Department of Biochemistry and Molecular Biology, University of Oviedo, Oviedo, Spain;

${ }^{6}$ University Institute of Biotechnology of Asturias, University of Oviedo, Oviedo, Spain ${ }^{7}$ Institute for Sanitary Research of the Princedom of Asturias (ISPA), Oviedo, Spain

*Corresponding author: E-mail address: costa@uniovi.es

Phone: +34985103488 


\section{KEYWORDS}

Alzheimer's Disease; Dementia; p53 protein; Unfolded p53; Electrochemical immunosensor; Plasma samples.

\section{ABSTRACT}

Alzheimer's disease is one of the most common causes of dementia nowadays, and its prevalence increases over time. Because of this, accurate methods for the analysis of specific biomarkers for an early diagnosis of this disease are much needed. Recently, the levels of unfolded isoform of the multifunctional protein p53 in plasma have been proved to increase selectively in Alzheimer's Disease patients in comparison with healthy subjects, thus entering the list of biomarkers that can be used for the diagnosis of this illness.

We present here the development of an electrochemical immunosensor based on nanostructured screen-printed carbon electrodes for the quantification of unfolded p53 in plasma samples. The sensor shows a suitable linear range (from 2 to $50 \mathrm{nM}$ ) for its application in real blood samples and a very low limit of detection (0.05 nM). The concentration of unfolded p53 has been accurately detected in plasma of elderly people in healthy conditions, subjects with mild cognitive impairment ( $\mathrm{MCl})$ and Alzheimer's Disease (AD) subjects, obtaining results with no significant differences to those provided by an ELISA assay. This result supports the possibility of measuring unfolded p53 levels with a cheap, simple and miniaturized device with a promising future for point-of-care applications in the early diagnosis of Alzheimer's dementia. 


\section{INTRODUCTION}

Nowadays, Alzheimer's disease $(A D)$ is a major global public health challenges facing our society. It is the most common type of dementia (represents $50-75 \%$ of all dementias). Its prevalence is increasing worldwide: approximately 47 million people live with this type of dementia around the world, and this number is projected to increase to more than 131 million by 2050 [1-3]. $A D$ is a progressive neurodegenerative disorder related to aging: approximately, it is suffered by $1 \%$ of people between 65 and 69 years old and it is higher than $50 \%$ in individuals above 95 years old [4]. The most characteristic symptoms of AD are difficulties with memory, language, problem-solving and other kind of cognitive skills which affect the person's ability to perform daily activities [5]. These symptoms increase with time, and they can reflect the degree of damage in human brain. The $A D$ degenerative process may start approximately 20 or 30 years before the clinical diagnosis of the disease. Early cognitive alterations defining a mild cognitive impairment $(\mathrm{MCl})$ that is not altering daily life, may often precede $A D$ dementia, but does not allow the identification of a specific type of neurodegenerative disorder $[6,7]$.

An accurate and early diagnosis for the $A D$ process would be very important in the treatment of the dementia, both in terms of slowing the progress of the disease and helping to prepare the patients and their family for the future. There is not a single test for the diagnosis of dementia: specialists use different approaches by obtaining medical family history, conducting cognitive tests, using brain imaging or blood tests, to discard other causes of the symptoms such as tumours or different vitamin deficiencies [5]. Therefore, the recommended medical approach to diagnose dementia 
remains a battery of tests for cognitive and behavioural evaluation. Consequently, AD cannot be clinically diagnosed until dementia is well established and a definitive diagnosis of AD must wait post mortem autoptic brain analysis and the identification of the histological changes originally described by Alois Alzheimer $[8,9]$. Because of this, it is increasingly important the identification of different proteins responsible for neurodegeneration that could help in the diagnosis and management of AD. This kind of proteins, named biological markers or biomarkers, are detectable or measurable indicators of different biological processes, pathogenic processes or pharmacological responses to therapeutic interventions. They can be found in biological tissues or fluids, as blood or cerebrospinal fluid, and their clinical utility is defined by the sensitivity, specificity and ease of use $[10,11]$. In order to be useful for diagnosis, a biomarker should be able to differentiate those mild cognitive impairment (MCl) patients, still autonomous, who will eventually progress into AD or into a moderate dementia due to other factors [12].

Nowadays, among all the biomarkers considered useful in routine diagnosis of AD in human cerebrospinal fluid (CSF), the most common are tau protein (total tau and phosphorylated tau at threonine 181) and amyloid beta 1-42 (Aß42). Both can reflect the neuropathology development and progression in AD and $\mathrm{MCl}$ [13-16]. Tau protein is a microtubular-associated protein, located in the neuronal axons, that facilitates the regulation of the transport of organelles to and from synapses, especially mitochondria; its transport is essential for having a correct synaptic function $[8,17,18]$. On the other hand, accumulation of amyloid beta 1-42 into plaques is demonstrated to be related with $A D[19,20]$. $A \beta 42$ is secreted as a result of the proteolytic cleavage by different secretases of the amyloid precursor protein (APP). In this way, this protein 
produces toxic oligomeric species and aggregate forming plaques, affecting the neurotrophic and neuroprotective properties of the brain [8,21-23]. The determination of the presence in the CSF of both total and phosphorylated tau and $A \beta 42$ is currently performed in order to provide further evidence to support the diagnosis of $A D$ and the progression from $M C l$ to $A D$, although the results are often inconsistent. With respect to these two biomarkers, recent work has demonstrated the superiority of using neuroimaging by fluorodeoxyglucose (FDG)-positron emission tomography (PET) in association with statistical parametrical mapping (SPM) in predicting the progression to $A D$ and non-AD dementias [24]; while a $90 \%$ accuracy prediction of conversion of cognitively normal older subjects to either $\mathrm{MCl}$ or $\mathrm{AD}$ within 2-3 years, has recently been obtained by measuring the plasma concentration of 10 lipids [25]. Also, in a very recent study, Preische et al. [26] have reported that levels of the protein neurofilament light chain were decreased in both CSF and blood serum of presymptomatic familial Alzheimer's patients and these changes were detectable over 16 years before the onset of disease symptoms, confirming the potential usefulness of biomarkers for dementia diagnosis.

A particularly interesting blood biomarker for $A D$ has been described by Uberti et al. [27]. These authors observed that compared to fibroblasts from healthy patients, fibroblasts from patients with $A D$ expressed much higher levels of a conformationally altered (unfolded) p53 protein (called mutant-like p53) [28]. While p53 is a multifunctional protein involved in a large number of biological processes for maintaining genomic integrity, and preventing tumoral growth following potentially genotoxic stimuli by exhibiting antioxidant activities in order to eliminate oxidative stress and ensure cell survival [29-31], several studies support the role of its unfolded 
conformation in the pathogenesis of $A D[23,27,32-34]$ and its potential as useful biomarker of the disease.

Immunofluorescence studies in peripheral blood cells have also helped to differentiate one antibody, PAb240, which binds to the primary epitope only accessible in the unfolded isoform of the protein [30,35,36] (see Figure S1 in Supporting Information). Thus, the use of this PAb240 antibody can allow the detection of conformationally altered p53 in patients and correlated to different stages of the disease [37].

In this work, it is developed an electrochemical immunosensor based on a gold nanostructured screen-printed carbon electrode (SPCE) as transducer and PAb240 as selective recognition element for the easy quantification of unfolded p53. The biosensor consists in a competitive immunoassay carried out on the SPCEs using the enzyme alkaline phosphatase as label and a mixture of 3-indoxyl phosphate with silver ions as substrate. Analytical signal is based on the anodic stripping of the enzymatically reduced silver $\left(\mathrm{Ag}^{0}\right)$. The biosensor is successfully applied, for the first time and without the need of any dilution, in plasma samples from aging people in cognitive healthy conditions or suffering either $\mathrm{MCl}$ or $\mathrm{AD}$. 


\section{EXPERIMENTAL}

\subsection{Apparatus and electrodes}

Disposable screen-printed carbon electrodes (SPCEs) are provided from Metrohm Dropsens. These electrodes are composed by a conventional three-electrode configuration, printed on a ceramic substrate: working and auxiliary electrodes are made of carbon ink, while the pseudoreference electrode is made of silver. The SPCEs are connected to the potentiostat through suitable connectors also purchased from Metrohm Dropsens.

Gold nanostructuration on SPCEs is done with a $\mu$ Stat 8000 potentiostat (Metrohm Dropsens), interfaced to a computer system and controlled by DropView 8400 software.

Voltammetric measurements are carried out using an ECO Chemie $\mu$ Autolab type II potentiostat/galvanostat (Metrohm Autolab) interfaced to a computer system and controlled by the NOVA version 2.1 software.

All the measurements performed in this paper were carried out at room temperature.

\subsection{Reagents and solutions}

Tris(hydroxymethyl)aminomethane (Trizma ${ }^{\circledR}$ base), magnesium nitrate hexa-hydrate, albumin from bovine serum (BSA), silver nitrate $\left(\mathrm{AgNO}_{3}\right)$ and streptavidin from Streptomyces avidinii labelled with alkaline phosphatase (S-AP) were purchased from Sigma-Aldrich. Gold standard $\left(\mathrm{HAuCl}_{4} \cdot 3 \mathrm{H}_{2} \mathrm{O}\right.$ in $\left.12.7 \% \mathrm{HCl}\right)$, fuming hydrochloric acid 
$(\mathrm{HCl})$ and nitric acid $\left(\mathrm{HNO}_{3}\right)$ were obtained from Merck. 3-indoxyl phosphate disodium salt was delivered by Biosynth.

p53 monoclonal antibody (PAb240) was purchased from Thermo Fisher Scientific. Unfolded p53 peptide and biotin-conjugated unfolded p53 peptide was synthetized and furtherly conjugated with biotin by Abyntek Biopharma.

All chemical reagents used in experiments were of analytical grade and used without further purification. Ultrapure water $(18.2 \mathrm{M} \Omega)$, obtained from a Millipore Direct- $\mathrm{Q}^{\circledR} 3$ UV purification system from Millipore Ibérica S.A, was used throughout all the work. Working solutions of PAb240 monoclonal antibody, BSA, unfolded p53 peptide, unfolded-p53 peptide labelled with biotin (p53-bio) and S-AP were prepared in $0.1 \mathrm{M}$ Tris- $\mathrm{HNO}_{3}$ buffer, $\mathrm{pH} 7.2$ (buffer 1 ). Working solutions of $3-\mathrm{IP}$ and $\mathrm{AgNO}_{3}$ were prepared in $0.1 \mathrm{M}$ Tris- $\mathrm{HNO}_{3} \mathrm{pH} 9.8$ buffer containing $2 \mathrm{mM} \mathrm{Mg}\left(\mathrm{NO}_{3}\right)_{2}$ (buffer 2) and stored protected from light. Buffer solutions are prepared every week and stored and $4{ }^{\circ} \mathrm{C}$, whereas working solutions needed for the immunoassay were prepared daily.

\subsection{Procedures}

\subsubsection{SPCEs nanostructuration}

Gold nanostructures are in situ generated onto the working electrode by electrochemical reduction of $\mathrm{AuCl}_{4}{ }^{-}$following a method previously optimized by our research group [38]. The procedure consists in depositing an aliquot (40 $\mu \mathrm{L})$ of $1 \mathrm{mM}$ $\mathrm{HAuCl}_{4}$ solution (in $0.1 \mathrm{M} \mathrm{HCl}$ ) on the electrode surface (covering the three electrodes) and applying a constant current intensity of $-100 \mu \mathrm{A}$ during $180 \mathrm{~s}$. This leads to the formation of nanostructures on the working electrode covering it with monodisperse AuNPs with a mean diameter of $75 \mathrm{~nm}$. Then, the nanostructured electrodes are 
washed with ultrapure water and they are ready for use. This procedure for gold nanostructuration is performed at room temperature and, using the $\mu$ Stat 8000 potentiostat, it can be performed in eight different SPCEs at the same time.

\subsubsection{Calibration of the immunosensor for the detection of the unfolded p53 peptide}

A scheme of the different steps of the biosensor can be seen in Figure 1. With this design, different optimizations (concentration of antibody, labelled peptide or bovine serum albumin for the blocking step) have been done. The following procedure (Figure 1) describes an optimized assay.

The working area of the nanostructured SPCE (AuNP-SPCE) is functionalised by physical adsorption coating it with $10 \mu \mathrm{L}$ of $4 \mu \mathrm{g} \mathrm{mL}^{-1}$ PAb240 antibody solution and incubating overnight, protected from light, at $4{ }^{\circ} \mathrm{C}$. The non-adsorbed antibodies are removed rinsing the electrode with buffer 1 and then, the antibody-free surface sites are blocked with $40 \mu \mathrm{L}$ BSA solution (2\%) for $30 \mathrm{~min}$. The electrode is washed again using buffer 1 and a $40-\mu \mathrm{L}$ drop of unfolded p53 peptide of varying concentrations is added and left to react with the antibody for 1 hour. After a washing step with buffer 1 an aliquot of $40 \mu \mathrm{L}$ of the biotinylated p53 peptide in a fixed concentration (10 nM) is deposited and let it react for 1 hour. In this step, all the antibodies that did not react with free p53 peptide before, reacted with the biotinylated p53 peptide. Then, the electrode is rinsed with buffer 1 and $40 \mu \mathrm{L}$ of S-AP of a fixed concentration ( $0.5 \mathrm{nM})$ is added.

After a washing step with buffer 2 , the enzymatic reaction is carried out depositing on the AuNP-SPCE $40 \mu \mathrm{L}$ of a mixture of $0.5 \mathrm{mM}$ 3-IP and $0.2 \mathrm{mM}$ silver nitrate solution. 
The enzymatic reaction takes place during $20 \mathrm{~min}$, and, after that, a linear sweep voltammetry is recorded, from $-0.1 \mathrm{~V}$ to $+0.4 \mathrm{~V}$ at a scan rate of $50 \mathrm{mV} \mathrm{s}^{-1}$.

\subsubsection{Real sample analysis}

The determination of unfolded p53 in blood samples was performed substituting, in the immunoassay protocol, the addition of the unfolded p53 peptide standard solution by the addition of the sample, in this case, blood plasma. Samples were kindly provided by the Unit of Neurology of the Alvarez-Buylla Hospital (Mieres, Asturias, Spain) and the Unit of Neurology of Cabueñes Hospital (Gijón, Asturias, Spain). A total of 12 plasma samples were tested: 4 cognitively healthy subjects (CHS), 4 patients with $\mathrm{MCl}$ and 4 patients with $\mathrm{AD}$. Subjects received a diagnosis of $\mathrm{AD}$ according to NINCDS/ADRDA criteria [39], while $\mathrm{MCl}$ diagnosis followed the criteria of Petersen: there has to be evidence of memory impairment, preservation of general cognitive and functional abilities and absence of any diagnosed dementia [40]. Healthy subjects were recruited from routine controls and had to meet the following criteria: i) no history of past or current psychiatric or neurologic disorders and ii) a score higher than 26 in the Mini-Mental State Examination (MMSE). All patients had undergone neuroimaging and neuropsychological assessment, and, depending on their specific clinical profile, other personalized tests were also performed. All of them (or their relatives) provided written consent for the participation in all the studies and were included in a previous study [41]. Blood samples have been processed as indicated by Arce-Varas et al. [41]:. plasma is obtained by Ficoll-Hypaque density gradient centrifugation and then aliquoted and stored at $-80^{\circ} \mathrm{C}$.

\section{RESULTS AND DISCUSSION}




\subsection{Optimization of experimental conditions}

A heterogeneous competitive immunoassay is adopted to construct the specific biosensor for the detection of unfolded p53. As transducer, SPCEs modified with electrogenerated gold nanoparticles are used since they have previously demonstrated better sensitivity than non-nanostructured SPCEs when bioassays using AP as label and mixture of 3-IP/Ag as substrate [42]. Moreover, these AuNP-SPCEs allow to develop single-use sensors (as the one here developed) due to their low-cost, portability and small size, being excellent for the development of point-of-care (POC) devices.

In order to achieve a selective immunosensor, the PAb240 antibody (capture antibody) is immobilized onto the AUNP-SPCE. The competitive immunoreaction is performed in two steps in order to increase the sensitivity: first, the sample is added on the AuNPSPCE functionalised with the capture antibody in a way the antigen (unfolded p53) present in the sample reacts with the antibody; then, the p53-bio ( $\mathrm{p} 53$ peptide labelled with biotin) is added to react with all the free antibodies (i.e. all the antibodies that were not occupied with unfolded p53 present in the sample). Thus, the higher the amount of unfolded p53 present in the sample, the lower the amount of p53-bio reacts with capture antibody and therefore, the lower the analytical signal.

To trace the immunoassay, the p53-bio is made to react with S-AP because of the strong non-covalent interaction that the system streptavidin-biotin provides. In this way, the enzyme AP is used as label and the mixture 3-IP/silver nitrate as enzymatic substrate. The silver enzymatic deposition catalysed by AP has been previously reported by our research group [43]. In the enzymatic reaction, AP hydrolyses 3-IP, producing and indoxyl intermediate. This intermediate reduces the silver ions present 
in the solution to metallic silver $\left(\mathrm{Ag}^{0}\right)$ and indigo blue. By this way, the enzymatically generated metallic silver is deposited on the surface of the electrode, and it can be detected by performing an anodic stripping scan and measuring the redissolution peak. The intensity current of this anodic peak is directly proportional to the concentration of p53-bio and therefore, inversely proportional to the concentration of unfolded p53 in the sample.

In order to achieve the best analytical features for the biosensor, experimental variables that affect its performance are optimized: i) the concentration of the blocking agent, ii) the concentration of the antibody PAb240 and iii) the concentration of p53bio.

Blocking agent. Bovine serum albumin (BSA) is used as a blocking agent to avoid nonspecific binding of proteins onto the surface of the electrode. Concentrations of BSA ranging from $1 \%$ to $3 \%$ are tested in experiments using fixed concentrations of PAb240 antibody $\left(4 \mu \mathrm{g} \mathrm{mL} L^{-1}\right)$ and of p53-bio $(10 \mathrm{nM})$. As shown in Figure 2, the use of BSA increases the signal-to-background ratio significantly, obtaining a maximum when $2 \%$ BSA is used. Based on these results, this concentration of BSA is used as blocking agent in the following steps of the biosensor construction.

Polyclonal antibody PAb240. Optimization of the concentration of the antibody PAb240 remains a key parameter, as too high amounts of the antibody reacting with a low concentrations of the unfolded p53 results in non-detectable analytical signals since there is enough antibody to react with the unfolded p53 present in the sample and with the bio-p53 added to obtain the signal. Therefore, it is important to make sure that a suitable limited concentration of capture antibody must be immobilized on 
the AuNP-SPCE in order to cause significant changes in the analytical signal in the case of different concentrations of unfolded p53 and therefore, low concentrations could be detected. Accordingly, different concentrations of PAb240 antibody are tested, and the results obtained are shown in Figure 3.

As can be seen, the highest analytical signal is obtained at a PAb240 antibody concentration of $4 \mu \mathrm{g} \mathrm{mL}^{-1}$, while the background signal remained at low levels at all PAb240 concentrations $\left(0-5 \mu \mathrm{g} \mathrm{mL}^{-1}\right)$ tested.

Biotin-conjugate p53 peptide. Different amounts of the biotin-conjugate p53 peptide are tested in order to establish the experimental conditions providing the highest efficiency of this electrochemical immunosensor. As seen in Figure 4, the highest peak current intensity signal values correspond to bio-p53 concentrations of $50 \mathrm{nM}$ and 100 $\mathrm{nM}$. However, $10 \mathrm{nM}$ is finally chosen as the optimum concentration of the bio-p53 because it consistently provides the signal with the best reproducibility, as error bars show. In addition, this is the highest concentration of the bio-p53 tested without saturating the electrode surface (Figure 4).

\subsection{Analytical characteristics of the immunosensor}

After the optimization of the main parameters involved in the design of the immunosensor, a calibration plot has to be carried out in order to know whether the immunosensor responds to increasing concentrations of the p53 peptide. The biosensor response against unfolded p53 concentrations between 2 and $50 \mathrm{nM}$ can be seen in Figure S2 (in Supporting Information), obtaining very well-defined 
voltammetric peaks (Figure 5A), and it is adjusted into a linear relationship (Figure 5B) within that range according to the following equation:

$$
\frac{i_{0}-i}{i_{0}}(\%)=37.7 \log [p 53](n M)-1.6
$$

The correlation coefficient obtained is 0.997 when measuring unfolded p53 concentrations in the range between 2 and $50 \mathrm{nM}$. The limit of detection (LOD) and the limit of quantification (LOQ), calculated as 3 or 10 times the standard deviation of the intercept divided by the slope are found to be 0.05 and $0.2 \mathrm{nM}$, respectively. These and other figures of merit are summarized in Table S1 (in Supporting Information).

In order to evaluate the reproducibility of this immunosensor, several biosensors are prepared in three different days and with different solutions of all the reagents, including the buffer solutions. As illustrated in Table S2 (in Supporting Information), the biosensor shows a very good reproducibility, with relative standard deviations (RSD) for three different concentrations of unfolded p53 (2, 10 and $50 \mathrm{nM})$ between $6.2 \%$ and $8.7 \%$.

\subsection{Real samples measurement}

The developed immunosensor is applied to determine the concentration of unfolded p53 in real plasma samples from patients who had been diagnosed with $\mathrm{MCl}$ or $\mathrm{AD}$ as well as from control subjects. There is no need for plasma dilution because p53 concentration in blood samples is within the calibration range of this biosensor, and blood plasma does not affect the sensitivity of the sensor. Samples have been processed as previously indicated (in Section 2.3.3). 
Values of unfolded p53 peptide levels obtained with the immunosensor are summarized in Table 1. For comparison, values for unfolded p53 determined in the same samples using direct Enzyme-Linked Immunosorbent Assay (ELISA) [41] are also reported. The values of unfolded p53 obtained with the immunosensor and the ELISA assay are very similar for all the samples tested with relative errors of below $8 \%$ in all the cases.

This confirms the usefulness of the developed immunosensor for the accurate detection of unfolded p53 in real samples. Therefore, this sensor offers a simple, miniaturized and cost-effective system for selective unfolded p53 quantification with the required sensitivity for its use in clinical samples.

As unfolded p53 is still an emerging biomarker for AD recently suggested, at present, there are not established cut-off values to discriminate between healthy, $\mathrm{MCl}$ and $A D$ subjects. However, the results provided by the sensor, in agreement with previous clinical studies $[6,27,28,33,37,41]$, show a clear tendency towards high amounts of unfolded p53 in plasma of $\mathrm{MCl}$ and $\mathrm{AD}$ patients when compared with plasma from control subjects. This increasing amount of unfolded p53 protein in AD subjects can be explained considering a higher pro-oxidant intracellular environment, which favours the formation of unfolded p53 [29,31].

To the best of our knowledge, this is the first biosensor for the quantification of unfolded p53 protein, which is a promising biomarker for the diagnosis of AD. Moreover, this sensor allows the quantification of unfolded p53 directly in human plasma without sample dilution. Other types of p53 protein biosensors can be found in the literature, but they are mainly focused on cancer detection [44-46] and don't 
distinguish between unfolded p53 from the "total". The biosensor here developed offers excellent figures of merit (as can be seen in Table S2 in Supporting Information) and has demonstrated great features for the quantification of unfolded p53 in plasma, which is a sample far less invasive than others used in $A D$ diagnosis such as cerebrospinal fluid.

\section{CONCLUSIONS}

In this work, we have developed a competitive immunosensor based on gold nanostructured screen-printed carbon electrodes for the quantification of unfolded p53 protein. In order to construct a selective sensor, a monoclonal antibody that only reacts with the unfolded isoform of the protein (whose concentration is higher in Alzheimer's Disease patients) has been employed as capture antibody. After the optimization of different parameters, a calibration curve has been obtained with excellent analytical characteristics (sensitivity, limit of detection and reproducibility). The developed sensor allowed measuring the unfolded p53 concentration in plasma samples from either patients with different neurodegenerative disorders (mild cognitive impairment or Alzheimer's Disease) or healthy patients with great accuracy. It is worthy to highlight that the sensor is able to directly quantify the unfolded p53 in plasma without dilution. Hence, the developed biosensor is a low-cost, simple, miniaturized and portable device that requires small amounts of sample; thus, it is a useful tool for decentralized unfolded p53 analysis contributing to future point-of-care applications that could help to the non-invasive diagnosis and monitoring of the progression of dementia and Alzheimer's disease.

\section{ACKNOWLEDGEMENTS}


This work has been supported by the FC-15-GRUPIN14-021 project from the Asturias Regional Government and the CTQ2014-58826-R and MINECO-18-CTQ2017-86994-R projects from the Spanish Ministry of Economy and Competitiveness (MINECO). O. Amor-Gutiérrez thanks Vicerrectorado de Investigación from University of Oviedo for the award of a grant "Ayudas para la realización de tesis doctorales" (PAPI-18-PF-13) through Plan de Apoyo y Promoción de la Investigación.

\section{SUPPLEMENTARY MATERIAL}

Supplementary data associated with this article can be found in the online version.

\section{REFERENCES}

[1] P. Scheltens, K. Blennow, M.M.B. Breteler, B. de Strooper, G.B. Frisoni, S. Salloway, W.M. Van der Flier, Alzheimer's disease, Lancet. Neurol. 388 (2016) 505-517. doi:10.1016/j.med.2019.03.012.

[2] M. Prince, A. Comas-Herrera, M. Knapp, M. Guerchet, M. Karagiannidou, World Alzheimer Report 2016: improving healthcare for people living with dementia, 2016. doi:10.13140/RG.2.2.22580.04483.

[3] A. Atri, The Alzheimer's Disease Clinical Spectrum: Diagnosis and Management, Med. Clin. North Am. 103 (2019) 263-293. doi:10.1016/j.mcna.2018.10.009.

[4] M. Racchi, D. Uberti, S. Govoni, M. Memo, C. Lanni, S. Vasto, G. Candore, C. Caruso, L. Romeo, G. Scapagnini, Alzheimer's disease: new diagnostic and therapeutic tools, Immun. Ageing. 5 (2008) 7-11. doi:10.1186/1742-4933-5-7.

[5] Alzheimer's Association, 2018 Alzheimer's disease facts and figures, Alzheimer's Dement. 14 (2018) 367-429. doi:10.1016/j.jalz.2016.03.001.

[6] C. Lanni, M. Racchi, S. Stanga, G. Mazzini, A. Ranzenigo, R. Polotti, M. Memo, S. Govoni, D. Uberti, Unfolded p53 in blood as a predictive signature of the transition from mild cognitive impairment to Alzheimer's disease, J. Alzheimer's Dis. 20 (2010) 97-104. doi:10.3233/JAD-2010-1347. 
[7] G. Peng, J. Wang, Z. Feng, P. Liu, Y. Zhang, F. He, Z. Chen, K. Zhao, B. Luo, Clinical and neuroimaging differences between posterior cortical atrophy and typical amnestic Alzheimer's disease patients at an early disease stage, Sci. Rep. 6 (2016) 1-11. doi:10.1038/srep29372.

[8] K. Blennow, Cerebrospinal fluid protein biomarkers for Alzheimer's Disease, J. Am. Soc. Exp. Neurother. 1 (2004) 213-225. doi:10.3233/JAD-2009-1177.

[9] H. Hippius, G. Neundörfer, The discovery of Alzheimer's disease, Dialogues Clin. Neurosci. 5 (2003) 101-108. doi:10.1145/1658550.1658558.

[10] M. Sjögren, N. Andreasen, K. Blennow, Advances in the detection of Alzheimer's disease - use of cerebrospinal fluid biomarkers, Clin. Chim. Acta. 332 (2003) 110. doi:10.1016/S0009-8981(03)00121-9.

[11] C. Humpel, Identifying and validating biomarkers for Alzheimer's disease, Trends Biotechnol. 29 (2011) 26-32. doi:10.1016/j.tibtech.2010.09.007.

[12] M. Degerman Gunnarsson, M. Ingelsson, K. Blennow, H. Basun, L. Lannfelt, L. Kilander, High tau levels in cerebrospinal fluid predict nursing home placement and rapid progression in Alzheimer's disease, Alzheimer's Res. Ther. 8 (2016) 22-31. doi:10.1186/s13195-016-0191-0.

[13] B. Shui, D. Tao, A. Florea, J. Cheng, Q. Zhao, Y. Gu, W. Li, N. Jaffrezic-Renault, Y. Mei, Z. Guo, Biosensors for Alzheimer's disease biomarker detection: A review, Biochimie. 147 (2018) 13-24. doi:10.1016/j.biochi.2017.12.015.

[14] N. El Kadmiri, N. Said, I. Slassi, B. El Moutawakil, S. Nadifi, Biomarkers for Alzheimer Disease: Classical and novel candidates' review, Neuroscience. 370 (2018) 181-190. doi:10.1016/j.neuroscience.2017.07.017.

[15] R. Sangubotla, J. Kim, Recent trends in analytical approaches for detecting neurotransmitters in Alzheimer's disease, Trends Anal. Chem. 105 (2018) 240250. doi:10.1016/j.trac.2018.05.014.

[16] B. Olsson, R. Lautner, U. Andreasson, A. Öhrfelt, E. Portelius, M. Bjerke, M. Hölttä, C. Rosén, C. Olsson, G. Strobel, E. Wu, K. Dakin, M. Petzold, K. Blennow, 
H. Zetterberg, CSF and blood biomarkers for the diagnosis of Alzheimer's disease: a systematic review and meta-analysis, Lancet. Neurol. 15 (2016) 673684. doi:10.1016/S1474-4422(16)00070-3.

[17] C. Tapia-Rojas, F. Cabezas-Opazo, C.A. Deaton, E.H. Vergara, G.V.W. Johnson, R.A. Quintanilla, It's all about tau, Prog. Neurobiol. 175 (2019) 54-76. doi:10.1016/j.pneurobio.2018.12.005.

[18] A.M. Pooler, W. Noble, D.P. Hanger, A role for tau at the synapse in Alzheimer's disease pathogenesis, Neuropharmacology. 76 (2014) 1-8. doi:10.1016/j.neuropharm.2013.09.018.

[19] T.L. Spires-Jones, B.T. Hyman, The Intersection of Amyloid Beta and Tau at Synapses in Alzheimer's Disease, Neuron. 82 (2014) 756-771. doi:10.1016/j.neuron.2014.05.004.

[20] A. Kaushik, R.D. Jayant, S. Tiwari, A. Vashist, M. Nair, Nano-biosensors to detect beta-amyloid for Alzheimer's disease management, Biosens. Bioelectron. 80 (2016) 273-287. doi:10.1016/j.bios.2016.01.065.

[21] T. Hu, C. Chen, G. Huang, X. Yang, Antibody modified-silver nanoparticles for colorimetric immuno sensing of $A \beta(1-40 / 1-42)$ based on the interaction between $\beta$-amyloid and Cu2+, Sensors Actuators, B Chem. 234 (2016) 63-69. doi:10.1016/j.snb.2016.04.159.

[22] S. Claeysen, J. Bockaert, P. Giannoni, Serotonin: A New Hope in Alzheimer's Disease?, ACS Chem. Neurosci. 6 (2015) 940-943. doi:10.1021/acschemneuro.5b00135.

[23] D. Uberti, G. Ferrari-Toninelli, S.A. Bonini, I. Sarnico, M. Benarese, M. Pizzi, L. Benussi, R. Ghidoni, G. Binetti, P.F. Spano, F. Facchetti, M. Memo, Blockade of the tumor necrosis factor-related apoptosis inducing ligand death receptor DR5 prevents $\beta$-amyloid neurotoxicity, Neuropsychopharmacology. 32 (2007) 872880. doi:10.1038/sj.npp.1301185.

[24] S.P. Caminiti, T. Ballarini, A. Sala, C. Cerami, L. Presotto, R. Santangelo, F. Fallanca, E.G. Vanoli, L. Gianolli, S. Iannaccone, G. Magnani, D. Perani, L. 
Parnetti, P. Eusebi, G. Frisoni, F. Nobili, A. Picco, E. Scarpini, FDG-PET and CSF biomarker accuracy in prediction of conversion to different dementias in a large multicentre $\mathrm{MCl}$ cohort, Neurolmage Clin. 18 (2018) 167-177. doi:10.1016/j.nicl.2018.01.019.

[25] M. Mapstone, A.K. Cheema, M.S. Fiandaca, X. Zhong, T.R. Mhyre, L.H. Macarthur, W.J. Hall, S.G. Fisher, D.R. Peterson, J.M. Haley, M.D. Nazar, S.A. Rich, D.J. Berlau, C.B. Peltz, M.T. Tan, C.H. Kawas, H.J. Federoff, Plasma phospholipids identify antecedent memory impairment in older adults, Nat. Med. 20 (2014) 415-418. doi:10.1038/nm.3466.

[26] O. Preische, S.A. Schultz, A. Apel, J. Kuhle, S.A. Kaeser, C. Barro, S. Gräber, E. Kuder-Buletta, C. LaFougere, C. Laske, J. Vöglein, J. Levin, C.L. Masters, R. Martins, P.R. Schofield, M.N. Rossor, N.R. Graff-Radford, S. Salloway, B. Ghetti, J.M. Ringman, J.M. Noble, J. Chhatwal, A.M. Goate, T.L.S. Benzinger, J.C. Morris, R.J. Bateman, G. Wang, A.M. Fagan, E.M. McDade, B.A. Gordon, M. Jucker, Dominantly Inherited Alzheimer Network, Serum neurofilament dynamics predicts neurodegeneration and clinical progression in presymptomatic Alzheimer's disease, Nat. Med. 25 (2019) 277-283. doi:10.1038/s41591-0180304-3.

[27] C. Lanni, D. Uberti, M. Racchi, S. Govoni, M. Memo, Unfolded p53: A potential biomarker for Alzheimer's disease, J. Alzheimer's Dis. 12 (2007) 93-99. doi:10.3233/JAD-2007-12109.

[28] D. Uberti, C. Lanni, T. Carsana, S. Francisconi, C. Missale, M. Racchi, S. Govoni, M. Memo, Identification of a mutant-like conformation of p53 in fibroblasts from sporadic Alzheimer's disease patients, Neurobiol. Aging. 27 (2006) 11931201. doi:10.1016/j.neurobiolaging.2005.06.013.

[29] S. Calmels, P. Hainaut, H. Ohshima, Nitric oxide induces conformational and functional modifications of wild-type p53 tumor supressor protein, Cancer Res. 57 (1997) 3365-3369.

[30] C. Méplan, M.J. Richard, P. Hainaut, Redox signalling and transition metals in the control of the p53 pathway, Biochem. Pharmacol. 59 (2000) 25-33. 
doi:10.1016/S0006-2952(99)00297-X.

[31] D. Liu, Y. Xu, p53, Oxidative Stress, and Aging, Antioxid. Redox Signal. 15 (2011) 1669-1678. doi:10.1089/ars.2010.3644.

[32] L. Buizza, C. Prandelli, S.A. Bonini, A. Delbarba, G. Cenini, C. Lanni, E. Buoso, M. Racchi, S. Govoni, M. Memo, D. Uberti, Conformational altered p53 affects neuronal function: Relevance for the response to toxic insult and growthassociated protein 43 expression, Cell Death Dis. 4 (2013) e484. doi:10.1038/cddis.2013.13.

[33] C. Lanni, M. Racchi, G. Mazzini, A. Ranzenigo, R. Polotti, E. Sinforiani, L. Olivari, M. Barcikowska, M. Styczynska, J. Kuznicki, A. Szybinska, S. Govoni, M. Memo, D. Uberti, Conformationally altered p53: A novel Alzheimer's disease marker?, Mol. Psychiatry. 13 (2008) 641-647. doi:10.1038/sj.mp.4002060.

[34] S. Stanga, C. Lanni, S. Govoni, D. Uberti, G. D'Orazi, M. Racchi, Unfolded p53 in the pathogenesis of Alzheimer's disease: Is HIPK2 the link?, Aging (Albany. NY). 2 (2010) 545-554. doi:10.18632/aging.100205.

[35] K.G. Wiman, K.P. Magnusson, T. Ramqvist, G. Klein, Mutant p53 detected in a majority of Burkitt lymphoma cell lines by monoclonal antibody PAb240, Oncogene. 6 (1991) 1633-1639.

[36] J.V. Gannon, R. Greaves, R. Iggo, D.P. Lane, Activating mutations in p53 produce a common conformational effect. A monoclonal antibody specific for the mutant form, EMBO J. 9 (1990) 1595-1602. doi:10.1002/j.1460-2075.1990.tb08279.x.

[37] L. Buizza, G. Cenini, C. Lanni, G. Ferrari-Toninelli, C. Prandelli, S. Govoni, E. Buoso, M. Racchi, M. Barcikowska, M. Styczynska, A. Szybinska, D.A. Butterfield, M. Memo, D. Uberti, Conformational Altered p53 as an Early Marker of Oxidative Stress in Alzheimer's Disease, PLoS One. 7 (2012) 1-11. doi:10.1371/journal.pone.0029789.

[38] G. Martínez-Paredes, M.B. González-García, A. Costa-García, In situ electrochemical generation of gold nanostructured screen-printed carbon electrodes. Application to the detection of lead underpotential deposition, 
Electrochim. Acta. 54 (2009) 4801-4808. doi:10.1016/j.electacta.2009.03.085.

[39] G. McKhann, D. Drachman, M. Folstein, R. Katzman, D. Price, E.M. Stadlan, Clinical diagnosis of Alzheimer's Disease: report of the NINCDS-ADRDA work group under the auspices of Department of Health and Human Services Task Force on Alzheimer's Disease, Neurology. 34 (1984) 939-944.

[40] R.C. Petersen, G.E. Smith, S.C. Waring, R.J. Ivnik, E.G. Tangalos, E. Kokmen, Mild cognitive impairment: clinical characterization and outcome, Arch. Neurol. 56 (1999) 303-308. doi:http://dx.doi.org/10.1212/01.CON.0000429175.29601.97.

[41] N. Arce-Varas, G. Abate, C. Prandelli, C. Martínez, F. Cuetos, M. Menéndez, M. Marziano, D. Cabrera-García, M. Fernández-Sánchez, A. Novelli, M. Memo, D. Uberti, Comparison of Extracellular and Intracellular Blood Compartments Highlights Redox Alterations in Alzheimer's and Mild Cognitive Impairment Patients, Curr. Alzheimer Res. 14 (2016) 112-122. doi:10.2174/1567205013666161010125413.

[42] E.C. Rama, M.B. González-García, A. Costa-García, Competitive electrochemical immunosensor for amyloid-beta 1-42 detection based on gold nanostructurated Screen-Printed Carbon Electrodes, Sensors Actuators, B Chem. 201 (2014) 567571. doi:10.1016/j.snb.2014.05.044.

[43] P. Fanjul-Bolado, D. Hernández-Santos, M.B. González-García, A. Costa-García, Alkaline phosphatase-catalyzed silver deposition for electrochemical detection, Anal. Chem. 79 (2007) 5272-5277. doi:10.1021/ac070624o.

[44] H. Fayazfar, A. Afshar, M. Dolati, A. Dolati, DNA impedance biosensor for detection of cancer, TP53 gene mutation, based on gold nanoparticles/aligned carbon nanotubes modified electrode, Anal. Chim. Acta. 836 (2014) 34-44. doi:10.1016/j.aca.2014.05.029.

[45] M. Pedrero, F.J.M. De Villena, C. Muñoz-San Martín, S. Campuzano, M. Garranzo-Asensio, R. Barderas, J.M. Pingarrón, Disposable Amperometric Immunosensor for the Determination of Human P53 Protein in Cell Lysates Using Magnetic Micro-Carriers, Biosensors. 6 (2016) 56-69. 
doi:10.3390/bios6040056.

[46] H. Afsharan, B. Khalilzadeh, H. Tajalli, M. Mollabashi, F. Navaeipour, M.-R. Rashidi, A sandwich type immunosensor for ultrasensitive electrochemical quantification of p53 protein based on gold nanoparticles/graphene oxide, Electrochim. Acta. 188 (2016) 153-164. doi:10.1016/j.electacta.2015.11.133. 


\section{CAPTION OF FIGURES}

Figure 1. Scheme of the immunosensing strategy for the detection of unfolded p53.

Figure 2. Effect of the BSA concentration in the peak current intensities obtained with the immunosensor in the absence and presence of p53 peptide (10 nM). Experimental conditions: PAb240 antibody $4 \mu \mathrm{g} \mathrm{mL}^{-1}$, p53-biotin-conjugated peptide $10 \mathrm{nM}$, S-AP 0.5 $\mathrm{nM}, 3-\mathrm{IP} 0.5 \mathrm{mM}, \mathrm{Ag}^{+} 0.2 \mathrm{mM}$. Data are given as average $\pm \mathrm{SD}(\mathrm{n}=3)$.

Figure 3. Effect of the PAb240 antibody (capture antibody) concentration in the peak current intensities obtained with the immunosensor in the absence and presence of p53 peptide (10 nM). Experimental conditions: BSA 2\%, PAb240 antibody $4 \mu \mathrm{gL}^{-1}, \mathrm{~S}$ AP $0.5 \mathrm{nM}, 3-\mathrm{IP} 0.5 \mathrm{mM}, \mathrm{Ag}^{+} 0.2 \mathrm{mM}$. Data are given as average $\pm \mathrm{SD}(\mathrm{n}=3)$.

Figure 4. Effect of the biotin-conjugate p53 peptide concentration in the peak current intensities. Experimental conditions: BSA 2\%, PAb240 antibody $4 \mu \mathrm{g} \mathrm{mL} \mathrm{L}^{-1}$, S-AP $0.5 \mathrm{nM}$, 3-IP $0.5 \mathrm{mM}, \mathrm{Ag}^{+} 0.2 \mathrm{mM}$. Data are given as average $\pm \mathrm{SD}(\mathrm{n}=3)$.

Figure 5. A) Linear sweep voltammograms recorded for different p53 peptide concentrations (up to down: $0,2,3,4,5,6,8,10,15,20,30,40$ and $50 \mathrm{nM}$ ) obtained with the immunosensor. B) Calibration plot of the immunosensor. Experimental conditions: BSA 2\%, PAb240 antibody $4 \mu \mathrm{g} \mathrm{mL}^{-1}$, p53-biotin-conjugated peptide $10 \mathrm{nM}$, S-AP $0.5 \mathrm{nM}, 3-\mathrm{IP} 0.5 \mathrm{mM}, \mathrm{Ag}^{+} 0.2 \mathrm{mM}$. Data are given as average $\pm \mathrm{SD}(\mathrm{n}=3)$. 
Table 1. Comparison of the unfolded p53 concentration values obtained using the biosensor here described and the ELISA, for real plasma samples from CHS (Control Healthy Subjects), $\mathrm{MCl}$ (Mild Cognitive Impairment) and AD (Alzheimer's Disease) patients. Data are given as average $\pm S D(n=3)$.

\begin{tabular}{|c|c|c|c|}
\hline \multirow[b]{2}{*}{ Sample } & \multicolumn{3}{|c|}{ Unfolded p53 (ng mL ${ }^{-1}$ ) } \\
\hline & $\begin{array}{c}\text { Immunosensor } \\
\text { (this work) }\end{array}$ & ELISA [41] & $\begin{array}{l}\text { Relative } \\
\text { error (\%) }\end{array}$ \\
\hline CHS1 & $5.0 \pm 0.8$ & 4.98 & -0.1 \\
\hline $\mathrm{CHS} 2$ & $5.6 \pm 0.3$ & 5.75 & 1.9 \\
\hline $\mathrm{CHS3}$ & $4.9 \pm 0.5$ & 5.01 & 1.2 \\
\hline CHS4 & $5.5 \pm 1.0$ & 5.93 & 7.9 \\
\hline MCl1 & $7.6 \pm 0.4$ & 7.96 & 4.8 \\
\hline $\mathrm{MCl} 2$ & $3.7 \pm 0.5$ & 3.86 & 4.1 \\
\hline $\mathrm{MCl} 3$ & $4.8 \pm 0.4$ & 5.02 & 3.4 \\
\hline $\mathrm{MCl} 4$ & $5.2 \pm 2.1$ & 5.07 & -2.1 \\
\hline AD1 & $6.0 \pm 0.7$ & 6.34 & 5.6 \\
\hline AD2 & $8.5 \pm 0.8$ & 9.05 & 5.9 \\
\hline AD3 & $9.3 \pm 0.8$ & 9.76 & 4.8 \\
\hline AD4 & $8.5 \pm 0.5$ & 8.86 & 4.1 \\
\hline
\end{tabular}




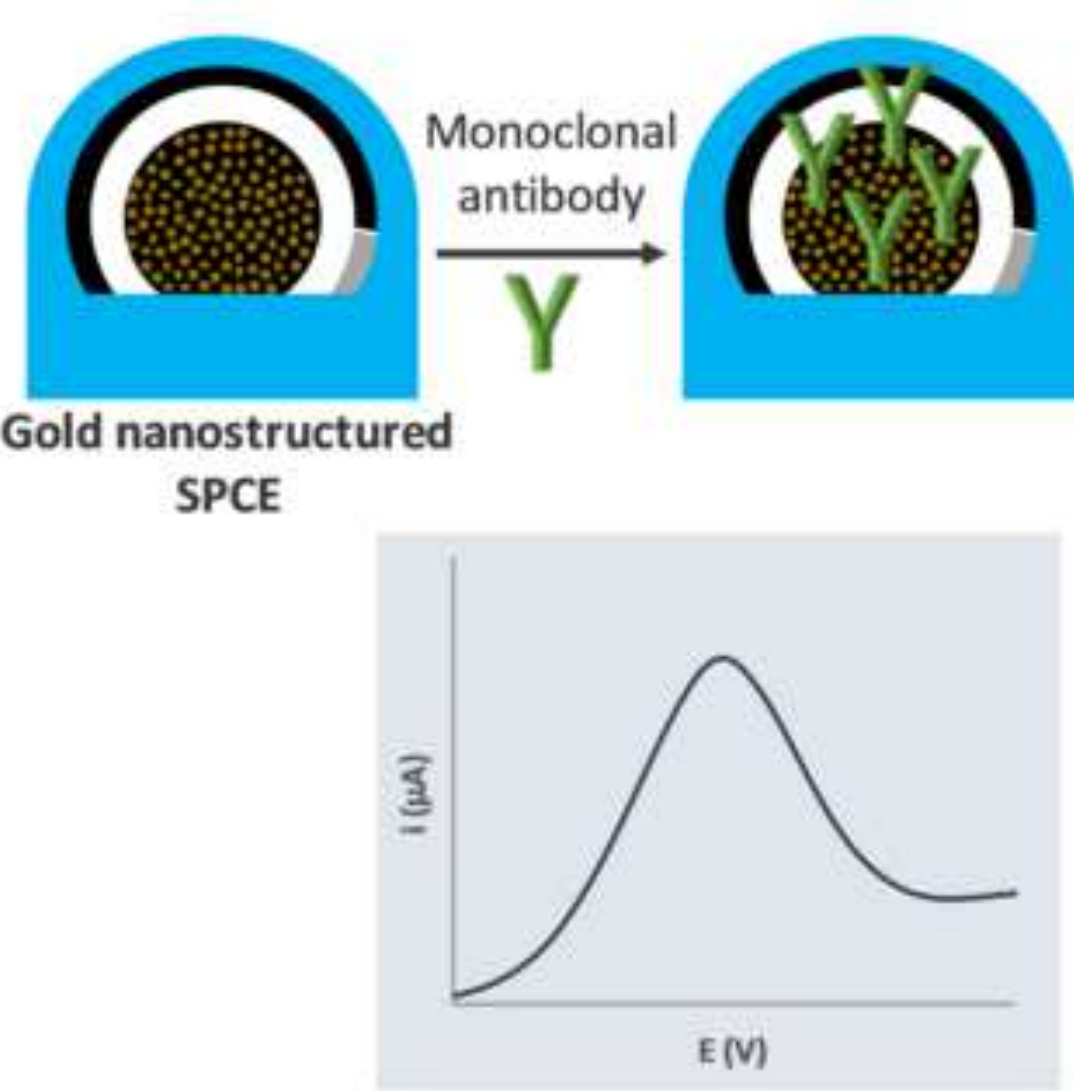

Electrochemical measurement

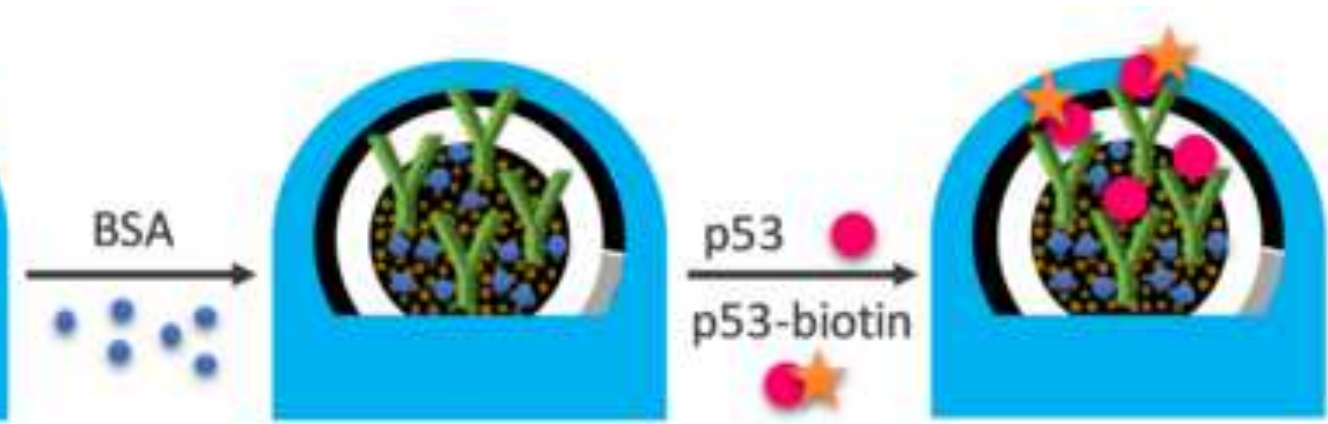

Blocking step

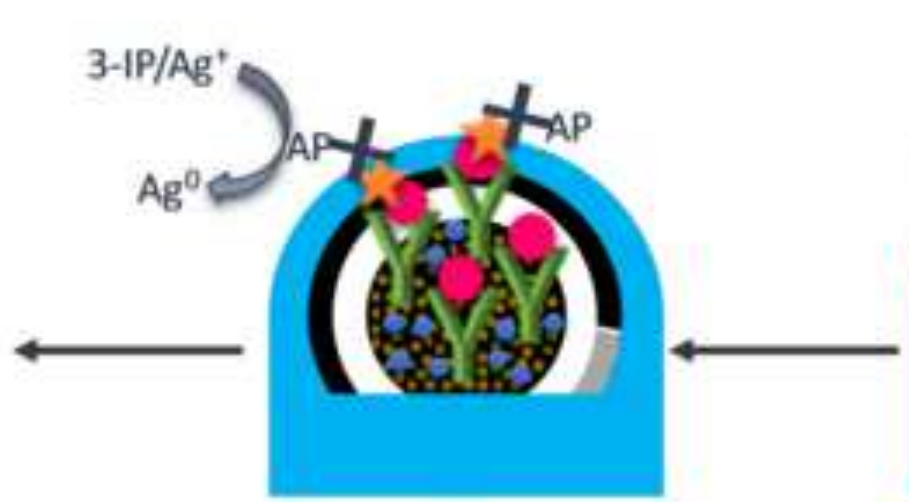

\section{Addition of} substrate
Competitive step

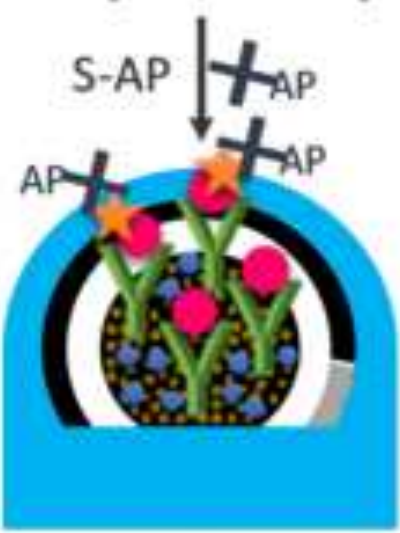

Addition of streptavidin-AP 
Figure 2
Click here to download high resolution image

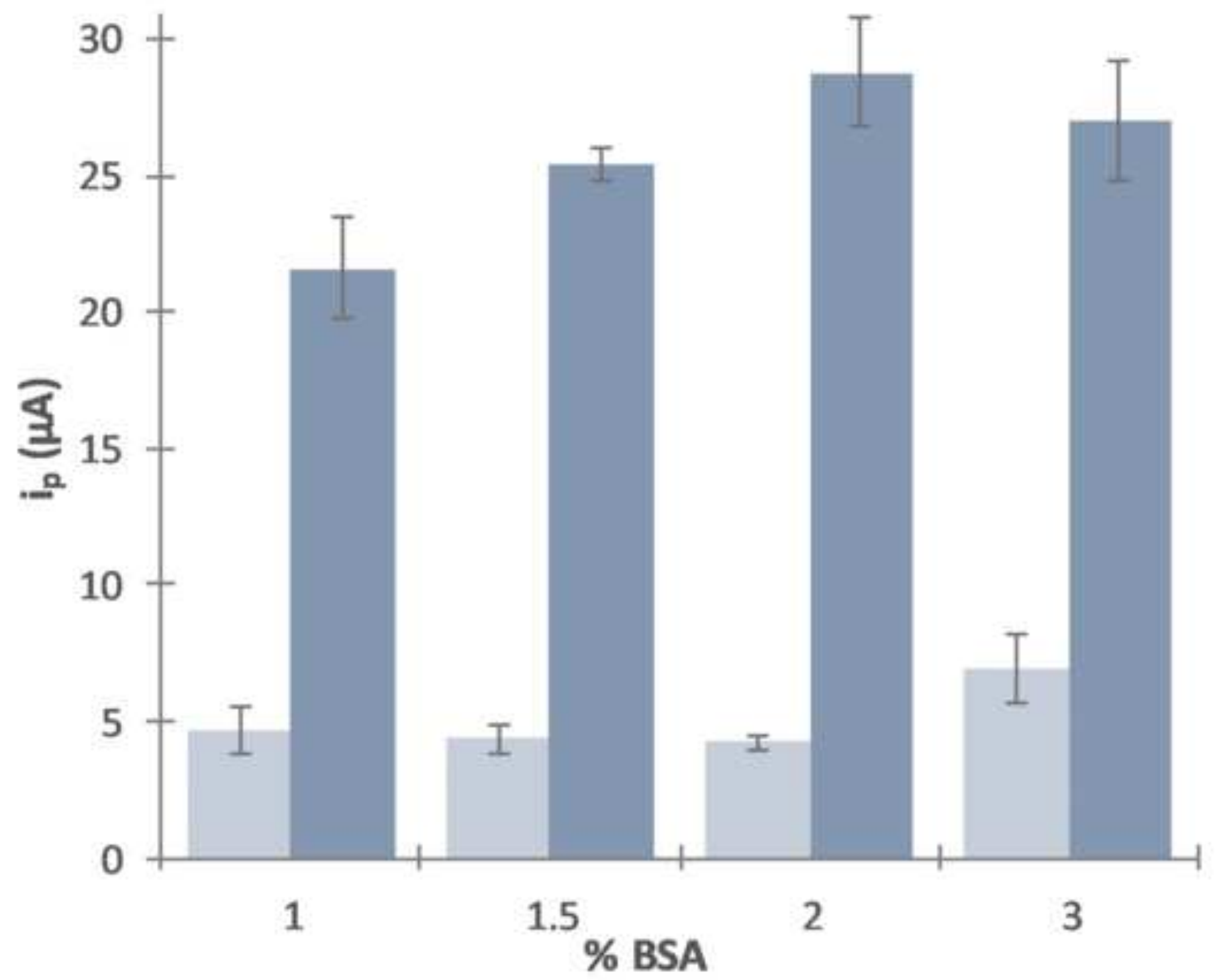

$0 \mathrm{nM} \mathrm{p53-bio}$

$10 \mathrm{nM}$ p53-bio 
Figure 3
Click here to download high resolution image

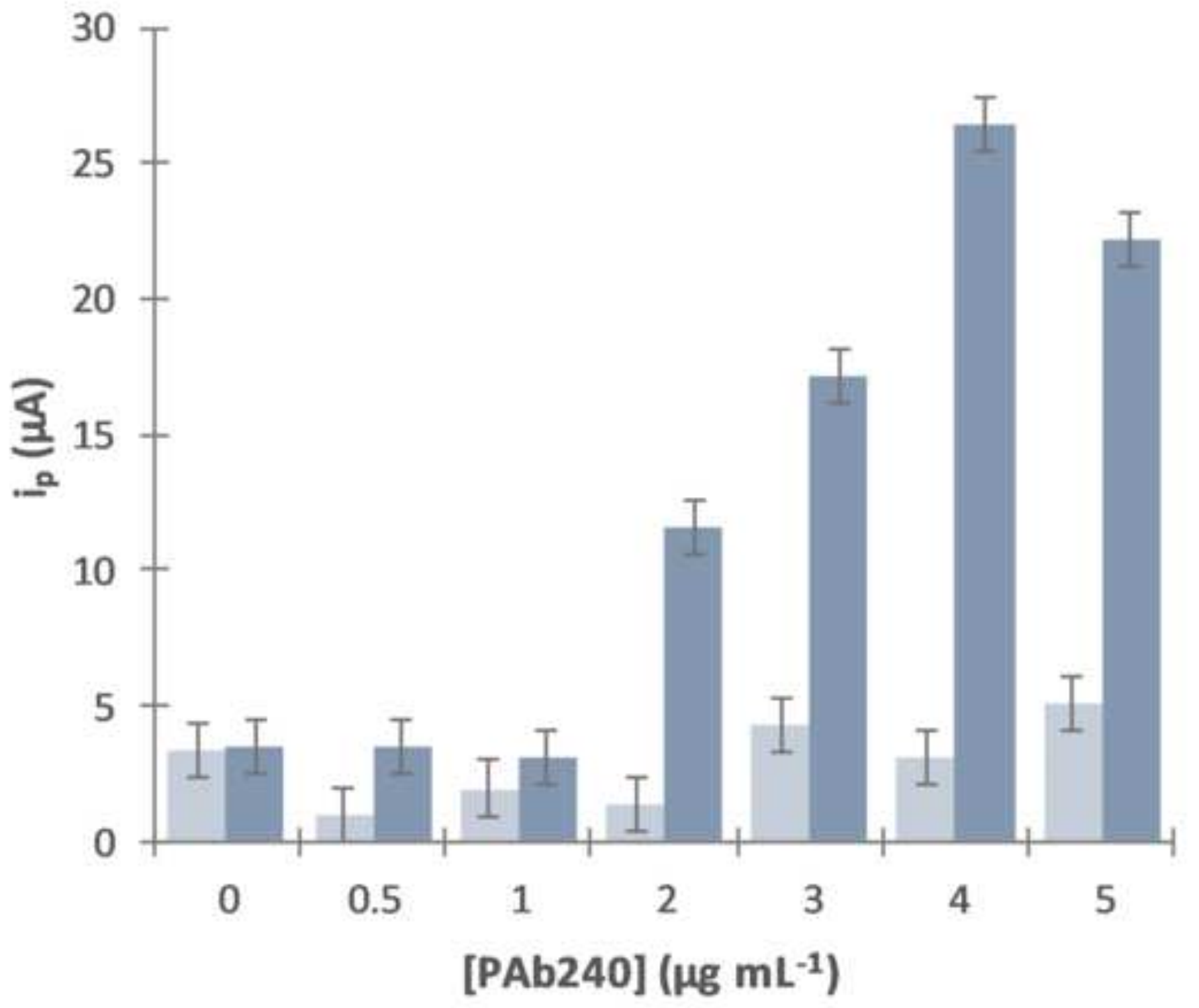

$0 \mathrm{nM}$ p53-bio

10 nM p53-bio 


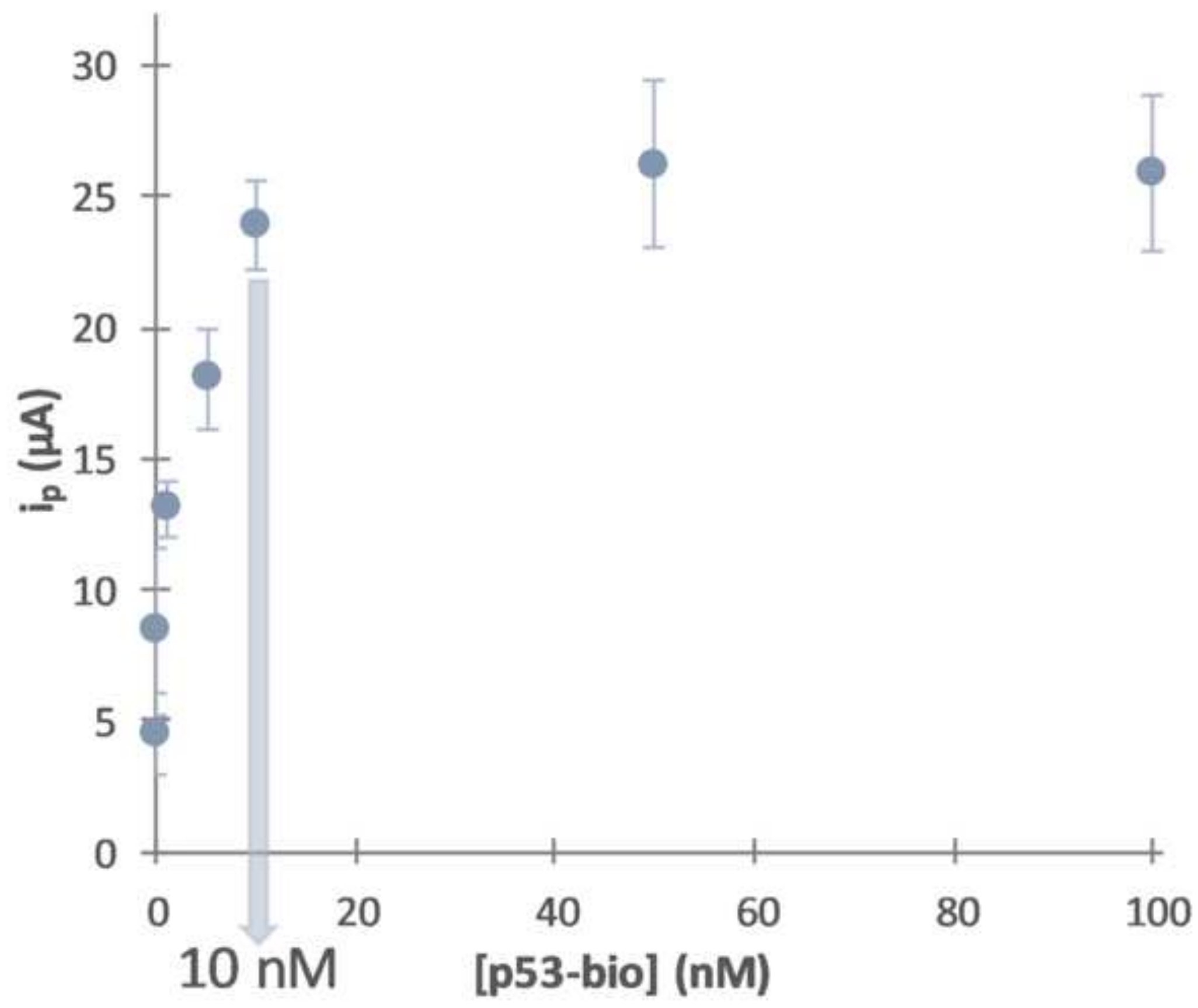


Click here to download high resolution image
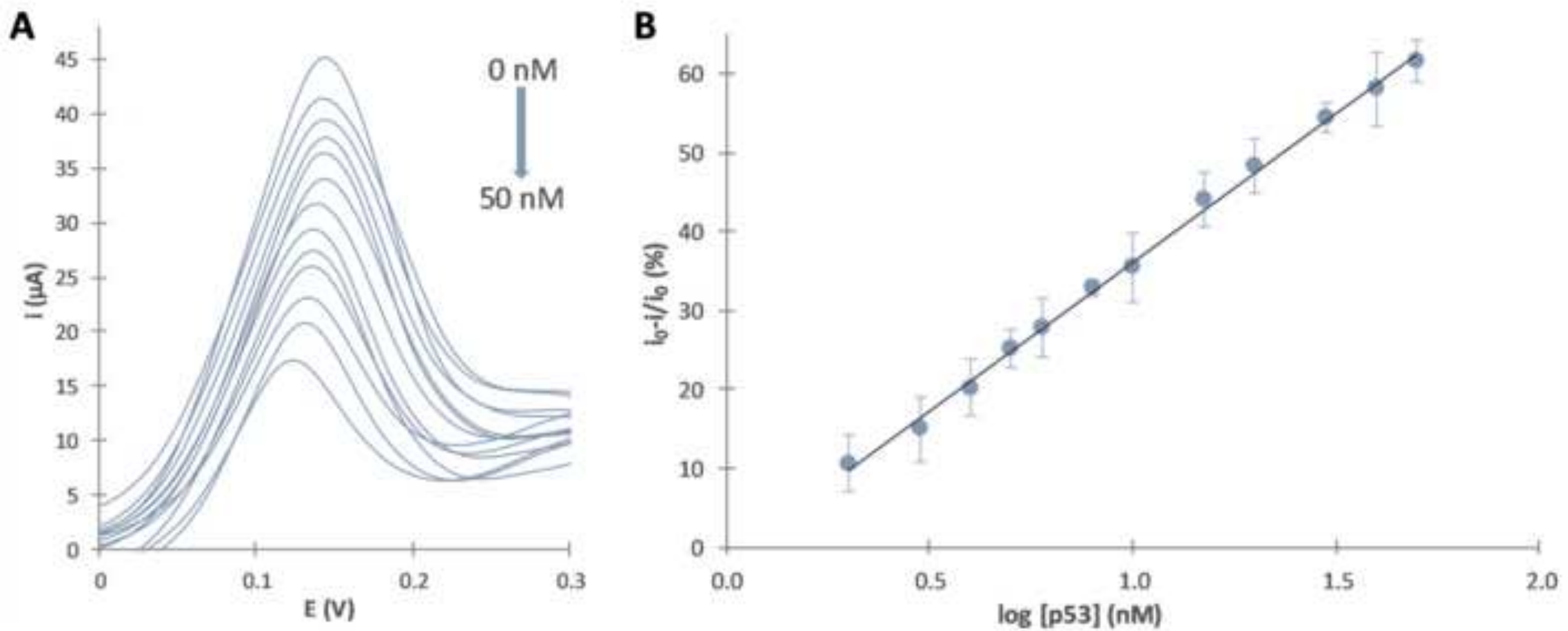